\title{
Using earthquakes to uncover the Earth's inner secrets: interactive exhibits for geophysical education
}

\author{
C. Nostro, G. Cultrera, P. Burrato, A. Tertulliani, P. Macrì, A. Winkler, C. Castellano, P. Casale, F. Di Felice, \\ F. Doumaz, A. Piscini, P. Scarlato, M. Vallocchia, A. Marsili, L. Badiali, A. Bono, S. Stramondo, L. Alfonsi, E. Baroux, \\ M. G. Ciaccio, and A. Frepoli \\ Instituto Nazionale di Geofisica e Vulcanologia, via di Vigna Murata 605, 00143 Rome, Italy
}

Received: 23 August 2004 - Revised: 6 December 2004 - Accepted: 7 December 2004 - Published: 16 June 2005

\begin{abstract}
The Educational \& Outreach Group (E\&O Group) of the Istituto Nazionale di Geofisica e Vulcanologia (INGV) designed a portable museum to bring on the road educational activities focused on seismology, seismic hazard and Earth science. This project was developed for the first edition of the Science Festival organized in Genoa, Italy, in 2003.

The museum has been mainly focused to school students of all ages and explains the main topics of geophysics through posters, movie and slide presentations, and exciting interactive experiments. This new INGV museum has been remarkably successful, being visited by more than 8000 children and adults during the 10 days of the Science Festival. It is now installed at the INGV headquarters in Rome and represents the main attraction during the visits of the schools all year round.
\end{abstract}

\section{Introduction}

Italy is a land prone to high seismic and volcanic hazards. About $60 \%$ of the country is classified as seismic on current hazard maps and has suffered more than 200 damaging earthquakes in the last century. Large cities such as Naples and Catania are located near the two major active volcanoes of Europe, Mt. Vesuvius and Mt. Etna, respectively. Italy is also the land where, historically, the first scientific observations and studies on seismic events and volcanic eruptions were made (e.g.: Plinius Secundus, first century A.D.; De Dolomieu, 1785; Mallet, 1862), and where many words now used in the scientific language were invented. Nevertheless, in spite of this long-lived cultural heritage, subjects such as seismology and volcanology are neglected in today schoolbooks and school programs. For this reason many schoolteachers feel the need to request visits to academic and scientific institutions with their class, for geophysical talks

Correspondence to: C. Nostro

(nostro@ingv.it) and exhibitions. They also need to gather up-dated educational material to upgrade school programs.

The Istituto Nazionale di Geofisica e Vulcanologia (INGV) is currently the largest European scientific institution dealing with research and real-time surveillance, early warning and forecast activities in geophysics and volcanology. Five years ago, the Educational and Outreach Group (E\&O Group) was created in the INGV headquarters of Rome to promote, develop, and disseminate Earth science programs and geophysical knowledge. Every year more than 4000 students from primary, secondary, and high schools visit the INGV centre in Rome during more than 65 open days, and demand increases each year. This group also participates in exhibitions and outreach projects organized by several public and private institutions.

In the last few years, the attention of scientific word to outreach in geophysics has grown, as demonstrated by many international projects and other activities performed by research institutes (Burrato et al., 2003; Johnson, 1999; Tertulliani and Donati, 2000; Virieux, 2000; Hamburger et al., 2001) and by the special sessions held at the international conferences as AGU meetings, EGU General Assembly and ESC General Assembly (DiDa Working Group, 2002; Nostro et al., 2004; Tertulliani et al., 2004). Moreover, in 2003 Genoa has been the capital of the scientific outreach with the first edition of Science Festival ("Festival della Scienza") in Italy. The Festival lasted for 10 days and included more than 180 events, such as scientific and technological exhibits, educational activities, lectures and videos. The large success of the initiative includes the Festival in the European Scientific Week, a European Union network of the VI Framework Program (http://www.festival.infm.it/it/home.php).

In this paper we describe the educational project developed by the E\&O group for the 2003 Genoa Science Festival: a portable museum designed to bring on the road educational activities focused on seismology, seismic hazard and Earth Sciences. The exhibits include activities that allow visitors to play back famous historical earthquakes, understand where and why earthquakes happen, discover the 


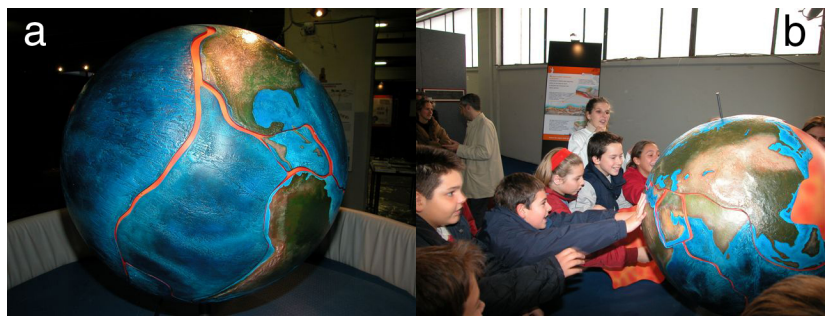

Fig. 1. (a) the 3-dimensional magnetic Plate Tectonic Puzzle; (b) children reconstructing the magnetic puzzle to learn the subdivision in plates of the Earth's lithosphere.

relationships between earthquake locations and plate boundaries, produce their own earthquakes and track recent earthquake activity.

\section{The exhibit elements}

The visitors follow a guided tour that starts with a short movie showing the location of the largest Italian earthquakes during the last 1000 years, conceived to illustrate the most seismic prone areas in Italy. In the first section, PC programs and posters introduce the visitors to the Plate Tectonics theory. Here an interactive program working on three desktop PCs illustrates where and when earthquakes and volcanic eruptions occurred from 1960 to the present. In the next exhibit the visitors can put down and reconstruct a 3dimensional magnetic plate tectonic puzzle. This exercise helps to better understand the Earth's surface configuration and constrains the concept of the Earth's lithosphere subdivision in plates. Another 3-dimensional Earth model shows the inner structure of our planet and the secret engine driving the plates.

After having been introduced to the plate tectonics' world, the visitors become familiar with earthquake geology and seismology. They play with a 3-D strike-slip fault model that can produce earthquakes of different sizes and, finally, produce their own earthquakes jumping close to an S-13 seismometer connected to a drum recorder. The tour ends with an exciting visit to the reproduction of the INGV National Seismic Network Center, watching seismic data in real-time and how seismologists locate the earthquakes.

Let's explore together the interactive museum.

\subsection{When and where did earthquakes happen in Italy?}

The entrance of the museum is a small movie-theatre where a 3-minutes movie shows the location of the largest Italian earthquakes during the last 1000 years, conceived to illustrate the most seismic areas in Italy. In the last 10 centuries Italy was struck by more than 200 earthquakes with magnitude greater than 5.5 (CPTI - Catalogo Parametrico dei Terremoti Italiani, 2004) and many cities were completely destroyed, sometimes abandoned and re-built in other places. In Italy even moderate size earthquakes can be damaging, and so it is important to study this level of seismicity.

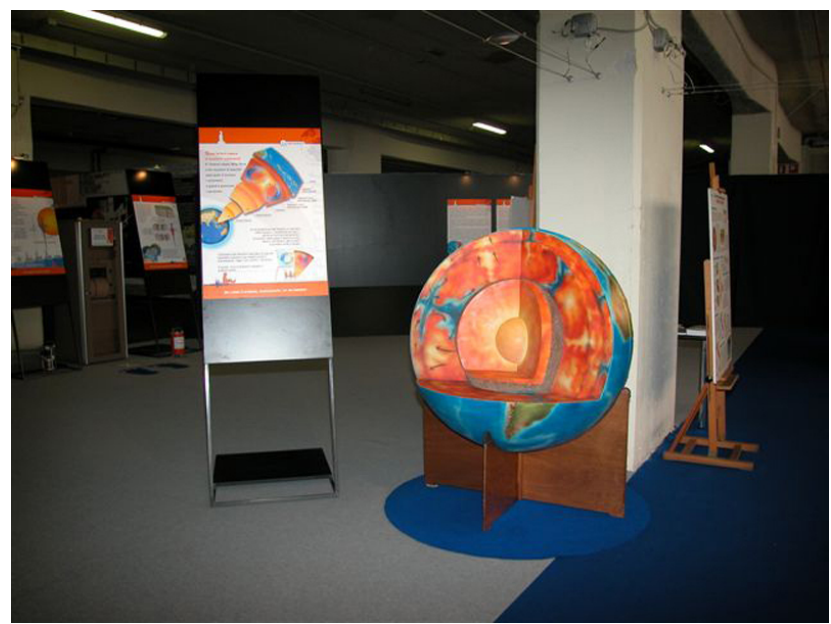

Fig. 2. A 3-dimensional Earth model shows what drives the plates and the inner structure of our planet.

Looking at the magnitude and location of historical events and considering the effects of major earthquakes in different parts of our country, the visitors can learn that earthquakes and damage do not occur by chance, and Earth often shakes where it has already shaken in the past.

\subsection{Where do earthquakes happen in the World?}

After the film the visitors move on to three computer stations connected to a database of earthquakes and volcanic eruptions, covering a time span from 1960 to present. The educational computer program was developed by Alan Jones (see also Jones et al., 2003) and was translated into Italian and modified to add the largest Italian earthquakes. When the program starts, the user is presented with a map of the world where he can choose the area and the number of earthquakes and volcanic eruptions which are to be displayed each second. Plates boundaries can be shown to point out the relationships between earthquake locations and the plate boundaries. The visitors are generally impressed by the huge amount of earthquakes occuring all over the Earth and discover that the earthquakes and eruptions location are not random.

\subsection{What about Earth's lithosphere?}

The third step is a 3-dimensional magnetic Plate Tectonic Puzzle (Fig. 1). Visitors can position several magnetic plates on a sphere of 1-meter in diameter, representing the Earth globe. The magnetic pieces illustrate the eight largest tectonic plates with their boundaries and can remain on the globe only if positioned in the right location. Thanks to this exhibit visitors can touch by hands and experience that the Earth's lithosphere is presently subdivided into single plates whose boundaries and positions are clearly identified. This was one of the favorite "games" of the younger children, who spent lots of time trying to set up the puzzle. 


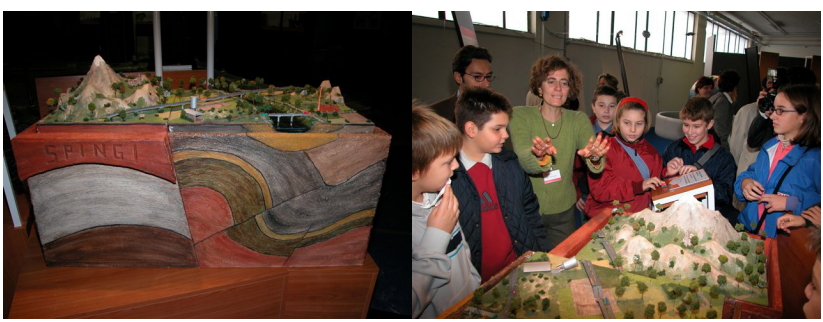

Fig. 3. An interactive 3-D electro-mechanical model of a 1 meterlong strike-slip fault.

\subsection{The Earth's interior and the plates engine}

After learning the subdivision of the lithosphere in plates, the visitors go to a 3-dimensional Earth model where the inner structure of our planet is shown (Fig. 2). The model shows also the mantle convection that moves the plates. This exhibit explains that the Earth is made up of many layers characterized by different temperatures, densities, and viscosities, and that the convection currents are the driving force behind the movement of the plates.

\subsection{How do earthquakes occur?}

The previous exhibits have explained where and why seismicity occurs. The visitors now enter the section where it is shown how earthquakes happen and what kind of damage they can produce. A 3-dimensional reconstruction of a fault zone reproduces a rupture that causes a damaging earthquake (Fig. 3). This exhibit is a 3-D electro-mechanical model of a 1 meter-long strike-slip fault made by two blocks representing the hanging-wall and foot-wall of the fault. The surface is realistically rendered with buildings, factories, bridges and trees. When one of the two blocks is pushed, it slips, causing the rupture along a vertical plane. The stronger the push, the larger the damage at the surface: trees and constructions fall down and can be recovered by pressing a button.

With this experience it is possible to understand how different forces produce different-magnitude earthquakes and that the level of damage is also related to the energy of the earthquake.

\subsection{JumpQuake}

Another way to experience the energy released by an earthquake is to produce a ground motion and look at it through seismometer records. By jumping on the ground in front of an S-13 seismometer, people create their own earthquakes that are recorded mechanically on a large rotating drum (Fig. 4). This simple interactive exhibit introduces the concept of seismic waves, their amplitudes and duration, displaying the trace of ground motion directly on paper. Moreover, it shows the instrumentation used by the National Seismic Network and how it works. This exhibit was particularly appreciated by children, who loved jumping higher and higher to induce the greatest earthquake of all. The 3$\mathrm{D}$ model of the fault and the seismometer is made simple to

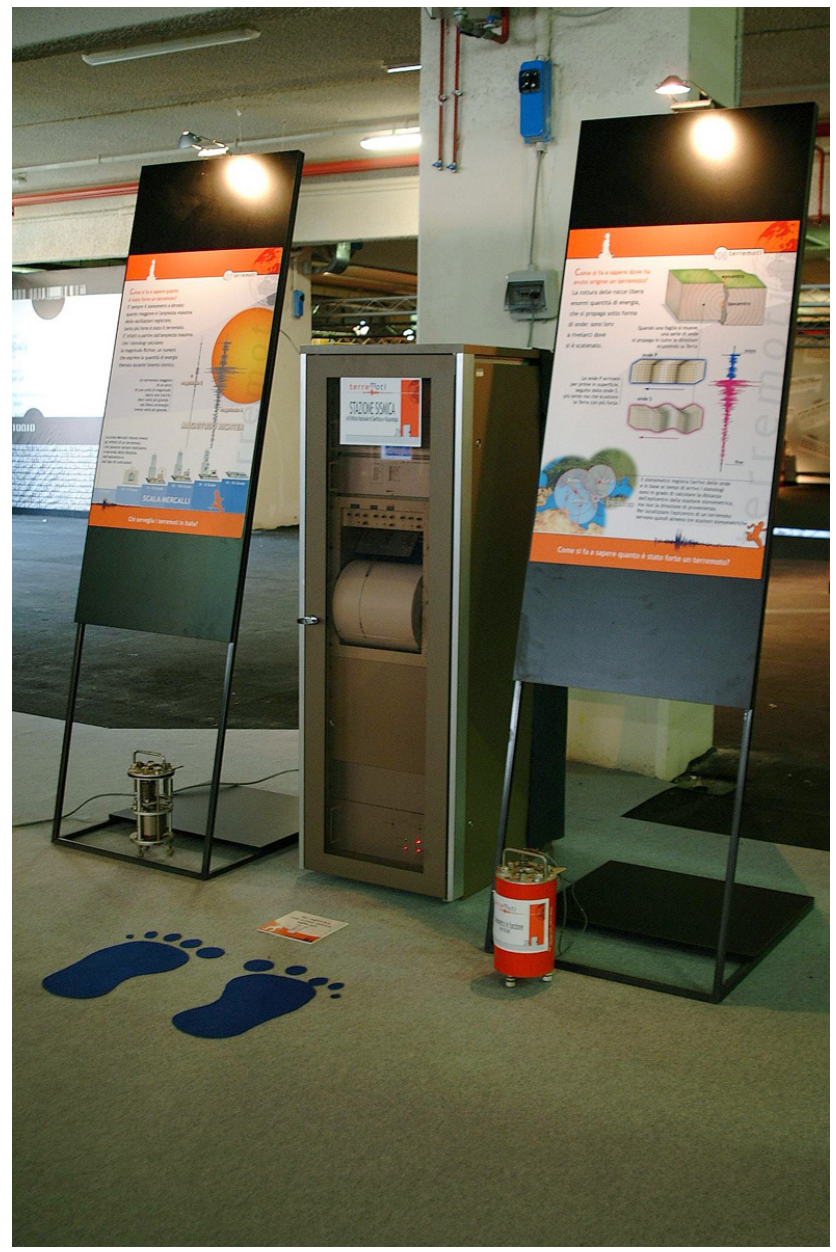

Fig. 4. By jumping in front of a S-13 seismometer connected to a drum recorder, people induce their own earthquakes.

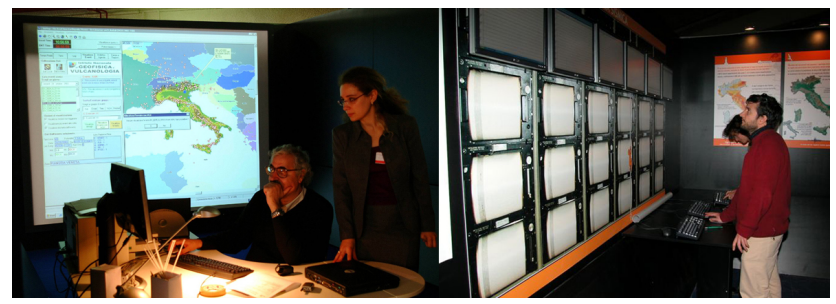

Fig. 5. The reproduction of the INGV National Seismic Network Center shows the seismic records in real-time and how seismologists locate the earthquakes.

make visitors understand the relationships between the force applied (stress) and the effect (earthquakes and permanent deformation of the surface).

\subsection{The INGV National Seismic Network Center}

The tour ends with an exciting visit to the reproduction of the INGV National Seismic Network Center, where it is possible to watch the seismic records in real-time and how seismologists locate the earthquakes (Fig. 5). Several computers are linked with the acquisition system of the National Seismic Network run in different headquarters of the INGV. 
The time series of the ground velocity recorded in realtime by the Italian Seismic Network stations are shown on six large monitors. Visitors can also see the earthquake waveforms as they occur and how the earthquake location is computed using a software developed at INGV (Bono and Badiali, 2005).

People discover the large number of earthquakes recorded everyday and they are amazed because earthquakes are usually thought as not frequent but always damaging. They learn that earthquakes are common phenomena on the Earth and they are the signals of the geological forces of our planet.

\section{Conclusions}

One of the main goals of our exhibition was to familiarize people with earthquakes, following a journey from their origin to the monitoring and study of those phenomena. This is important for natural disaster preparedness in a country with a high exposure, like Italy. The public reactions were in general of wonder to know how many earthquakes hit Italy in historical time (they usually just remembered the last two or three earthquakes occurring in the past 20 years), and of curiosity to see how the seismic monitoring is performed.

We choose to use very few computer animations in designing our tour, preferring hands-on exhibits to provide the opportunity to directly interact with the phenomena. We think that in this way the curiosity is much more stimulated, and the number of visitors and their feedback seems to demonstrate the success of this experience. The 3-D mechanical displays and the real-time earthquake information help to understand what links the processes ruling the dynamic Earth and seismicity and volcanic activity.

To give an idea of the expenses sustained for the creation of this traveling mini-museum and of the effort for the participation to an event such as the 2003 Genoa Science Festival, let's try to give some figures. The cost of the design and construction completely financed by INGV, was about 150000 EUR. The ongoing costs for transportation and maintenance, were around 4000 EUR to move it from Rome to Genoa. The number of people needed to staff the exhibits is variable according to the attendance, but on average with a visit every 15 min 8 people were necessary to guide and illustrate the exhibits. Each visit lasted at least 1 hour. We organized the staff in several watches of 4-5 days, and the total number of researchers and technicians who dedicated their time was 30 people.

Our future plans are to follow this experience and design new exhibits dealing with other fields of geophysics (such as Geomagnetism and Volcanology) to provide an all-around comprehension of the planet Earth. Up to now, we designed for the 2004 Genoa Science Festival a new exhibit tour dealing with the Earth's magnetic field (Winkler et al., 2004).

Edited by: V. Rosmorduc

Reviewed by: A. Jones and R. Stein

\section{References}

Bono, A. and Badiali, L.: PWL Personal WaveLab 1.0, an ObjectOriented workbench for seismogram analysis on Windows Systems, Computers \& Geosciences, 31, 1, 2005.

Burrato, P., Casale, P., Cultrera, G., Landi, P., Nappi, R., Nostro, C., Scarlato, P., Scotto, C., Stramondo, S., Tertulliani, A., Winkler, A., and Bonifaci, U.: Geophysics for Kids: The Experience of the Istituto Nazionale di Geofisica e Vulcanologia, Seismological Research Letters, 74, 5, 529-535, 2003.

CPTI Working Group: Catalogo parametrico dei terremoti italiani, GNDT-ING-SGA-SSN (Eds.), Tipografia Compositori (publ.), Bologna, 88 pp., 1999.

De Dolomieu, D.: Memoria sopra i tremuoti della Calabria dell' anno 1783, Neaples, 1785.

DiDa Working Group INGV: Educational Geophysics at INGV Rome, Italy - EOS Trans. AGU, 83 (47), Fall Meeting Suppl., Abstract ED52A-0004, 2002.

Hamburger, M., Pavlis, G. L., Phinney, R. A., Steinberg, D., Owens, T. J., and Hall-Wallace, M.: New science education initiative brings seismology into the classroom, EOS - Trans. AGU, 82, 266-267, 2001.

Johnson, C.: Seismology and education: The IRIS Education and Outreach Program, GSA Today, 9, 8-10, 1999.

Jones, A. L., Braile, L. W., and Braile, S. J.: A Suite of Educational Computer Programs for Seismology, Seismological Research Letters, 74, 5, 605-617, 2003.

Mallet, R.: Great Neapolitan earthquake of 1857, Chapman and Hall, London, 1862.

Nostro C. and E\&O-INGV Group: Using earthquakes to uncover the Earth's inner secrets: interactive exhibits for geophysical education, ES2 Geo- and Space-physical Sciences (Education, Outreach and Defining Users), Abstr.-No. EGU04-A-06276, European Geosciences Union 1st General Assembly, Nice, 25-30 April 2004

Plinius Caecilius Secundus (minor): Epistolarum libri decem, edited by: Mynors, R. A. B., Oxford, 1968.

Tertulliani, A. and Donati S.: A macroseismic network of schools for the collection of earthquake effects in a large city, Seismological Research Letters, 71, 536-543, 2000.

Virieux, J.: Educational Seismological Project: EDUSEIS, Seismological Research Letters, 71, 530-535, 2000.

Tertulliani, A., Nostro, C., Macrì, P., Winkler, A., Castellano, C., Burrato, P., Casale, P., Cultrera, G., Scarlato, P. G., Doumaz, F., Piscini, A., Di Felice, F., Vallocchia, M., Stramondo, S., Badiali, L., Alfonsi, L., Baroux, E., Ciaccio, M. G., Frepoli, A., and Marsili, A.: Interactive exhibit for geophysical education: earthquakes!, SS-3 Special session: Education and outreach, Abstr.No. SS-3 14, European Seismological Commission, XXIX General Assembly, Potsdam, September 2004.

Winkler, A. and the E\&O Group INGV-Roma: Fatal Attraction - a Discovery of the Earth Magnetic Field, Eos Trans. AGU, 85 (47), Fall Meet. Suppl., Abstract ED31C-0752, 2004. 